\title{
A Sonic Theory Unsuitable for Human Consumption
}

\section{Introduction}

The past decade has seen a proliferation in sound-based scholarship and the increasing significance of audio culture - as simultaneously a site for analysis, a medium for aesthetic engagement, and a model for theorization - which has been identified as 'the sonic turn' ${ }^{1}$ There is undoubtedly a current boom in sound art too, as, what John Kieffer calls, 'the new kid on the cultural block'. ${ }^{2}$ The increasing number of sonic courses, conferences, journals, art shows, and prestigious awards, which had hitherto been the sole privilege of the visual, point to an emerging audio culture that largely echoes an attempt to resist the tyranny of ocularcentrism. Sound festivals, courses, art shows, and prestigious awards that had hitherto been the sole privilege of the visual, all attest to an emerging audio culture that shows no signs of dying down. Perhaps, as Michele Hilmes puts it, the study of sound 'hailed as an 'emerging field' for the last hundred years, exhibits a strong tendency to remain that way-always emerging, never emerged'. ${ }^{3}$ Notably, the majority of this scholarship and cultural production focuses on the, sensory, methodological, economic, social, aesthetic, philosophical, and psychological dimensions of the subject, already covering a wide range of approaches.

Yet, sonic events do not only take place within the spectrum of the living and the perceptible, what we may call the life of sound. The sonic features a largely untouched but fascinating relationship, for example, to counterfactual and counterfictional thinking, to the zones of transmission between life and death, to subaquatic, Cthulu-esque, non-human forms of life, and to unsound, vibrational milieus inaccessible to the senses. I take for granted that, firstly, perceptible sound is only a subset of the broader vibrational continuum, and, secondly, an engagement with the sonic encourages the conceptualisation of a third dimension between theory and fiction. My article discusses alternative schemas daring to go beyond the audiophile anthropocentric angle by rethinking the 'if space' inbetween, what we all agree to be the real by consensus ad idem (i.e. what is known) and certain more unreal dimensions (i.e. non-actualised, or speculative). I understand the concept and method of 'sonic fiction'4 as situated in this third dimension, as that which channels the alien, unknown, and sometimes all-devouring unseen that lies beyond but has something significant to say about this world. The article centres on the following question: If, in sound studies, the sonic is consistently taken as that which we can hear, feel, or somehow perceive, as a result of something doing or something being (be it biological, artificial, or other), than how can we account for the sonic's immanent relationship to the uncertain, the unearthly and ultimately to the unknowable? The latter, I argue, can help prevent sound studies from becoming a selfcongratulatory, empty category onto which concepts are extrinsically applied; either trapped in a widely phenomenological and experiential paradigm or struggling to secure a place in the neo-realist arena (sonic realism).

\section{Does Sound Need a Field?}

Different writers have engineered different conceptual approaches to the sonic. Douglas Kahn, whose 1999 book Noise, Water, Meat was seminal in inciting the sonic turn, writes, 'By sound I mean sounds, voices and aurality - all that might fall within or touch on auditive phenomena, whether this involves actual sonic and auditive 
events, or ideas about sound and listening; sounds actually heard or heard in myth; sounds heard by everyone or imagined by one person alone; or sounds as they fuse with the sensorium as a whole'. ${ }^{5}$ Michael Bull and Les Back's recent follow-up to the original Auditory Culture Reader anthology, finds them continuing their search for deep listening: 'the need to attune the ears to the multiple cultural layers that might be embedded in any sound'. ${ }^{6}$ And in The Oxford Handbook of Sound Studies, Trevor Pinch and Karin Bijsterveld situate sound theory as part of the rise of 'sensory studies', which looks at the 'relationship between the material embedding and multisensory mediation of modern sound' ${ }^{7}$ These voices are symptomatic of a body of work that has developed as a way of making sense of massive changes in culture and technology from an explicitly sonic perspective. They constitute reactions to the primacy of Cartesian reason, showing ways of escaping the Western tendency to measure, calculate, and represent everything. They offer strategies for defending and resurrecting the nullified senses, like hearing, which must no longer surrender to the tyranny of ocularcentrism.

And there are yet other schemas, equally intriguing and perhaps less ideological. For example, Francis Dyson argues for an irreducible positivity to sounds as having their own ontological existence. For others, like Veit Erlmann, sound becomes a tool for revisiting old ideas from an entirely novel standpoint. Through the notion of resonance, Erlmann argues that sound, music and listening played a crucial role in the formation of Descartes' thought; and urges sound scholars and feminist writers to reevaluate his work as more than the formation of a disembodied rationality. Interestingly, Erlmann uses the term 'aurality', which considers both 'the materiality of perception' and the 'conditions that must be given for something to become recognized, labeled and valorized as audible in the first place' ${ }^{8}$

Even more radical approaches to the question of the sonic have come from theorists such as Steve Goodman, who argues for the privileging of vibrational force and sonic affect; sound coming to the rescue of thought, rather than the other way around, forcing it to vibrate. In my own work in The Rhythmic Event, I argue for the consideration of the sonic event as an instance of a different temporality subsisting underneath clock-time and sense perception. This book is an investigation into experimental projects that, by interweaving digital, sonic, and aesthetic dimensions, tap into a rhythmicity that offers us a glimpse into the unknown, indeterminate and unintentional forces immanent to sound. My work has been influenced significantly by Kodwo Eshun's interventions on sound, art, and afrofuturism, especially his 1998 book More Brilliant Than the Sun: Adventures in Sonic Fiction, which sets the stage for the redesigning of sonic reality.

From all this, it becomes clear that there are ample definitions, approaches and positions in the debate about what sound is, what it can do, how we come to know it, imagine it and define it. It is safe to assume that these are also under constant change, appropriately mutating not only to reflect the least static of realms, the sonic, but also to catch up with the plethora of conceptual frameworks that theorists have engineered through the years to capture it. Sound has been referred to both as a phenomenon out there in the world waiting to be absorbed by human ears, and, inversely, understood as a separate, dynamic entity. Sound has been addressed in terms of its physicality, materiality, ephemerality, spirituality, ghostliness, even unknowability. It has been the destination, the object, the process, the method, the archive, the means and the ends. 
Sounds have been studied 'in themselves', or as part of a field of vibration that exists in and of itself. Is sound inseparable from the position of the human who describes it? Or is it altogether a different planet that we may never know and which may know us more than we do it? It follows that pinning down, wrapping up and resolving the question of sound theory should not be an easy or, for us, welcome undertaking.

\section{Sonic Fiction}

Back to Kodwo Eshun's 1998 book, which begins with a double problem: firstly, the fact that futurism, the avant garde, electronic music, modernism, have all been attributed to the genius of white, middle class, heterosexual men, mostly, whilst black music has been tied to a stereotypical earthly, natural, primitive, soulful, back-to-theroots and struggling for inclusion by the human species narrative (as exhibited in present-day R\&B). Secondly, Eshun is fed up with the exclusion of digital rhythm, as he and others at Ccru experienced it at the dawn of 90s dance, drug and electronic music culture, and so, alongside the inclusion of AfroDiasporic futurism, he calls for the consideration of 'webbed network' of 'computerhythms', 'machine mythology' and 'conceptechnics', and the digital diaspora that routes, reroutes and criss-crosses the Black Atlantic, connecting the UK to the US, the Caribbean to Europe and to Africa. ${ }^{9}$ The Cybernetic Culture Research Unit, or Ccru, was active at the University of Warwick during the mid nineteen-nineties and it is known for its experimental blending of philosophy, fiction, art, science, and the esoteric. Digitalisation, cybernetics, science fiction, redefining sex/gender, and sonic subcultures were at the core of the group's research, who adopted the Deleuzoguattarian method of concept manufacture as the only purpose of (doing) theory.

Eshun's book is groundbreaking both for having brought afrofuturism to the attention of media studies, sound studies, cultural theory and philosophy, at least in the UK and albeit belatedly, and, crucially for this article, for deploying sonic fiction as its methodology. 'The term sonic fiction can be understood as the convergence of the organisation of sound with a fictional system whose fragments gesture towards but fall short of the satisfactions of narrative'. ${ }^{10}$ Add to this the Internet, a realm that excels in speculation, rumour and anonymity and you get an idea of how fictional tactics enter into the operational dynamics of the actual and are well suited to the indeterminable sphere of sound. For Eshun, 'A sonic fiction is assembled from track subtitles, the instructions in runout grooves, the statements on labels, the graphic images embedded within the support system of the record or the CD or the file, all of which feed into and reinforce each other to form a plane of consistency.' ${ }^{11}$ It brings together snippets of events, habits, objects, and processes at once pertaining to historicity and mythology. In this sense, Steve Goodman is right when he notes that sonic fiction is a subspecies of what the Ccru called 'hyperstition', the 'element of effective culture that makes itself real, through fictional quantities functioning as time traveling potentials. Hyperstition operates as a coincidence intensifier.' ${ }^{12}$ The Ccru coined the term merging the terms 'hyper' and 'superstition' conceive there is no difference in principle between a universe, a religion, and a hoax. All involve an engineering of manifestation, or practical fiction, that is ultimately unworthy of belief. Nothing is true, because everything is under production. Because the future is a fiction it has a more intense reality than either the present or the past. Ccru uses and is used by hyperstition to colonize the future, traffic with the virtual, and continually reinvent itself.' ${ }^{13}$ 
Sonic fiction is an unconventional research method, whose aim is to radicalise the speculative ghost in sound culture. It involves mobilising new levels of possibility space, invites concept manufacture, spawns new languages and demonstrates, as Eshun puts it, 'an extreme indifference towards the human'. ${ }^{14}$ Intertwined with the power of fictional spaces to unearth the secret life of things, sonic, or phono-fiction, tells the untold tales of theory. Musicians, philosophers, artists and writers who engage with the realm of sonic fiction, elicit the extremely experimental undercurrents of sonic investigation, so that their work does not only reflect a sonic reality but produces it. This approach bestows a power onto the text, the artwork, the music, or other entity, to leak into the real and to germinate it with affective worlds that might otherwise run parallel to it. More than examining, archiving, or glorifying the history and theory of sound, sonic fiction works at the continual intersection of speculative theory, science fiction, and science fact, or the ongoing computational/ AI present. The latter, as JG Ballard already knew, is yielding every possibility and therefore studying it must necessarily involve the recognition of what is real without being actual, simultaneously of this world and alien, even radically different from our habitual expectations and therefore unknowable. Having had only recently to come to terms with the unknowability of the world - as well as its existence without us and its complete indifference to us - sonic fictional methods become a form of disorientation proper to the study of the present. Entering the operational dynamics of the text/ artwork/ music itself, sonic fiction triggers a rupture to knowledge and the opening up of experience to a nonhuman realm. This is also the domain of MythScience, a field of research invented by Sun $\mathrm{Ra}$, sound and fiction making reality, proliferating improbability. ${ }^{15}$ Sun Ra, arguably the first afrofuturist, is one of those musicians whose work generates pop theory. Both his music and the film 'Space is the Place' (year), are pregnant with concepts that cut across the authority of Science and Philosophy and offer something 'greater than the truth', as Sun Ra believed. The ability of fiction (myth) to develop what is not rational, what is hidden and often left untouched by Science and Philosophy.

\footnotetext{
AUDINT

The speculative plots produced by the likes of Drexciya, Sun Ra, Underground Resistance, Rammellzee, and others, remain to this day largely unknown and not fully understood in term of their theoretical significance. We have yet to uncover the impact of their function as time-travel devices, rebooting the limits of space and time and virtually extending them into the future; no longer just the past haunting the contemporary but also the future appearing in the cracks of the present. Despite remaining largely unknown, their work continues, or is echoed rather, in other current schemata such as the research cells AUDINT (Audio Intelligence). Originally formatted in 1945, AUDINT currently consists of Toby Heys, Steve Goodman, Suzanna Zamfe, and Patrick Defasten. Their primary aim is to investigate the ways in which ultrasonic, sonic, and infrasonic frequencies are used to demarcate the soundscape and to subsequently perceive how their martial and civil deployments modulate psychological and physiological states. The information garnered from this research is subsequently utilised to enact installations, performances, books, and films.
} 
can be understood as In the case of AUDINT, the aim is to conduct theoretical and artistic experiments at the peripheral zones of sound and to investigate their impact on psychological and physiological states. These zones are what AUDINT refer to as unsound; audio-related phenomena in the wider vibrational spectrum that are capable of offering insights into the unknown aspects of perception.

A collection of AUDINT recordings, writings and illustrations were released in 2014 as Martial Hauntology, a project investigating frequency-related technologies and programs developed by military organisations since 1944, to orchestrate the spectral phenomena of haunting within the area of conflict. The first track 'Delusions Of The Living Dead' opens with a soft female voice that begins a phantom tour of the world of AUDINT, and their mission to steal the recipe for inducing extreme psychological disorders at will. In the modus operandi set by Philip K Dick, she may be talking about a recent discovery or something that does not exist at all, therefore she is free to say everything or nothing. She speaks of characters and events that inhabit real but counterfeit worlds, a disordered, delusional, alien intelligence, condemned to lurk in the shadows of the actualised world - the one which the majority of us evidently agree on. It's as if they present themselves to the narrator and demand that she lets them speak. Through a technique mastered by Ursula LeGuin, by naming the characters, places and events in the history of AUDINT, the voice causes them to exist in other people's minds, laying bare the slippage between invention and discovery.

Those who enter the world of AUDINT must succumb to the fact that they will never know whether they are driven away from or coming closer to the truth. The voice relays to them the schizophonic fact that there is not one truth and that they themselves may be nothing more than biological puppets, susceptible to experiment and recruitment by sonic forces outside their perception. Perhaps this should be called the AUDINT syndrome, at the polar extreme of the Cotard condition and of those who believe themselves to be dead, there are those suffering from the condition of being somebody, going somewhere, with something to do. Therefore the delusion is common to both the living and the living dead. The madness is shared; nobody comes out clean; nobody perhaps but the sonic algorithm IREX2. This, according to information released by AUDINT, is a vibrational self-aware AI entity challenging the limits of human knowledge to generate its own spacetimes, its own worldviews.

Through their sono-fictional interventions, AUDINT are sensing and teasing out other dimensions of reality lying tangent to this world, confirming the Ligottian suspicion that 'The only value of this world lay in its power-at certain times - to suggest another world'. ${ }^{16}$ This kind of extra-auditory thinking and practice suggests that theory, history, even time itself can be excavated from the virtual sphere of sound and its fictions. Working (thinking, producing) under its auspices, drives one to tap directly into the vibrational intelligence of the sonic, rather than settling for its cultural analysis. Books, records, artworks and other 'pathogenic strategies' 17 produced are proofs that, as Guattari suspected, 'aesthetic utterances can anticipate scientific advances by decades'. ${ }^{18}$ Sonic fictional strategies testify to the ways in which sonic thought and art strive to scout out something that runs counter to the normal order of things and out of which new configurations of reality emerge.

This could also be conceived as science-in-fiction: the diagrammatic operation of the complex between sonic fiction-extreme audio phenomena-and computational 
culture; where computation, after Luciana Parisi, is revealed to be a form of speculative thought in itself. ${ }^{19}$ Sonic fictional accounts express the memory of an unlived reality, arriving entire and intact, yet never before experienced. They are concerned with contaminating the factual record, offering alternative (hi)stories to the condemned - sonic fiction is after all a minor and micro art/ science/ method, best suited to a minority (black, female, other) people or a people yet to come. Against the anthropomorphism of artificial intelligence and the human-centric and maledominated orientation to sound studies, sonic fictional works plant the seed of speculation in our minds that the sonic might be an entity within its own right; with its own logic, its own thoughts and interventions.

\section{Theory-Fiction}

Fiction within theory texts (and vice versa) can be an effective way of recording encounters that take place at the nexus of imagination and argument. Theory fiction emerges when the activity of reasonable articulations of information becomes blocked. Fear of the finite takes hold and, at that point of pulsating energy, a membrane needs to be punctured. The membrane is the boundary between art fiction and theory, the puncturing equipment is the fictional deviation, announced (or not) by

The aforementioned sonic tactics expose a way of thinking and doing that goes beyond the divisions of truth and fiction, historicity and mythology, theory and imagination. Certainly, this isn't the sole privilege of sonic fiction; rather, the latter sits comfortably between methods of writing and practice that came before it, such as the, already mentioned, blurred line between invention and discovery favoured by Philip K Dick, the theory-fiction concerns of Baudrillard, or Barrington Nevitt's suggestions that "Fictions foreshadow facts". ${ }^{20}$ Sonic fiction is also on the same plateau with the intriguing area of counterfactual — and counterfictional - thinking, intersecting a wide range of disciplines and where fiction 'can be said to have the same cognitive value as scientific thought experiments' ${ }^{21}$; as well as with the philosophical writings of well-established theorists such as Foucault, or Alexius Meinong before him, and David Lewis or Donna Haraway, after him. The basic premise of this kind of thinking is that it both belongs to and helps expand a realm of argumentation and understanding that embraces speculative, fabulated, fictional methods without attributing to them a lesser degree of seriousness, validity and fruitfulness from any other type of argumentation.

In the case of Foucault, we know that the relationship between author and text is for him a complicated affair and one that goes against authoritarian claims to the truth, by history, science, or philosophy. Famously, Foucault has argued that 'I am no doubt not the only one who writes in order to have no face. Do not ask me who I am and do not ask me to remain the same.... ${ }^{22}$. His defence of the right to anonymity and fiction, is also supported elsewhere, as when he declares of The Order of Things 'My book is a pure and simple 'fiction': it's a novel, but it's not I who invented it; it is the relationship between our period and its epistemological configuration and this mass of statements. The subject is indeed present in the totality of the book, but he is the anonymous 'one' who speaks today in all that is said'. ${ }^{23}$ Deleuze too confirms that, 
'Foucault offers us less a discourse on his method than...the severe poetry of what is said, which subsumes both nonsense and the greatest profundities. In a certain way Foucault can declare that he has never written anything but fiction for, as we have seen, statements resemble dreams and are transformed as in a kaleidoscope, depending on the corpus in question and the diagonal line being followed. But in another sense he can also claim what is real, for everything is real in the statement, and all reality in it is openly on display.' 24

Sonic fiction's own inquiries and formulas are echoed in Foucault's Blanchotian evocation that 'it is now so necessary to think through fiction-while in the past it was a matter of thinking the truth' ${ }^{25}$ Eshun makes a similar point when he explores Drexciya's sono-fictional afrofuturist attempts to 'publicly withdraw from public'and at the same time 'making public that which is difficult to make out, an event, a figure, an appearance that can only be perceived obscurely'. ${ }^{26}$ Eshun explains that this is a condition of public secrecy whose purpose is to seek out the less obvious and to have acquired a taste for the periphery having always and already been situated there. In this sense, sonic fiction becomes a practice of taking obscurity, speculation, and unknowing seriously and mining them for the rigorous and solid ideas they may yield, when sufficient pressure is applied.

Generally, though there is currently a noticeable taste for speculation and obscurity in theory and art, there is little actual practice of it. Authors, artists, philosophers may like to talk about the power and intrigue of facelessness, the unknown, pseudonymity and anonymity, yet their work is by and large signed and credited under real names and individual ownership fiercely copyrighted. This problem is intensified with regards to sound studies material, which, as an only recently acknowledged and established academic discipline, in its struggle to leave behind obscurity seems to have acquired too much fondness for the light. However, there is work at home with opaqueness and the periphery, delivering what some speculative and theory-fictional accounts largely celebrate but often lack the conviction to see through in practice. Like Sun Ra, Underground Resistance, and Drexciya, AUDINT and others currently working on the edges and extremes of audiovisual theory and practice, are more concerned with contaminating the factual record, offering to those condemned to populate the darkest pages of history a way out. Sonic fiction can perhaps be seen as a weapon for the ostracised, used for unleashing the untold tales of history of an aquatic, underground or underworld people yet to come.

Certainly there is theoretical work situated (or considered to be) within the wider sound studies field that nevertheless is not quite at home with it or with any particular discipline. As already mentioned, Kodwo Eshun and Steve Goodman's ways of thinking and writing about sound are prime examples of this, as is Eldritch Priest, whose Boring, Formless, Nonsense develops an original theory of failure, uselessness and purposelessness, and of the value of lived abstraction exemplified by experimental music and sound. Accounts like these seek out and amplify the potential of thinking sonically and of incorporating parallel worlds, fabulations and fictions into the analysis of the sonic, in order to make you ask questions like, is this real or invented? Has it happened or is it about to happen? Does taking on sound vis-à -vis the fictive enable leakages between dreaming and reality or perhaps, as Rancière would have it, 'building new relationships between reality and appearance'?27 


\section{Facta Ficta}

The above discussion shows that an encounter with phono-fictional accounts, whether they recognise and label themselves as such or not, should leave the audience/ reader/ participant in a partial state of unknowing and ignorance. This is an altogether different way of approaching and producing knowledge from the one we are used to and certainly one that has and will continue to suffer many forms of attack-from science and philosophy alike. Yet such a debate becomes slightly more interesting when the relationship between fact and fiction is further explored, as with the aforementioned 'what if' of counterfactual thinking. Among other things, through the latter it is suggested that, 'counterfactuals achieve a contrast effect, as they sharpen the awareness of an actual state or outcome through the mental juxtaposition with a possible world' ${ }^{28}$ In addition, counterfictional thoughts are worth considering in the same vein, 'for which the fiction plays the role that the actual world plays for counterfactual thought as we know it. What is more, for some fictions, we can relate out counterfactional explanations of fictive facts to the real world in just the way in which we transfer the results of counterfactual thought experiments to the real world. Fiction, therefore, can be said to have the same cognitive value as scientific thought experiments'. ${ }^{29}$

Thus we are faced with two different but interrelated notions that a) fictions cannot teach us about the actual world and that there is no actual truth in them, and b) that science's holy grail of holding the truth is no more than a fiction, have been both endlessly explored by philosophical debates on the subject of truth and, on the other side, by disputes about the legitimacy of hypotheses in science. Not without relevance is the, also aforementioned, Meinongian objection to 'the prejudice in favour of the actual'. ${ }^{30}$ Meinong's preoccupation with the ontological status of non-existent entities has influenced philosophical theories of the object since it argues that 'fictions are necessary...The good writer's ability to discern what would really happen were some set-up incarnate is just a development of an ability that is fundamental to all cognition. Non-fictional, true propositions only get their content because the concepts involved can occur in true fictions' ${ }^{31}$ Yet, this is all not merely a matter of forcing reality to fit certain linguistic structures, but rather of elements of writing and practice that are only retrospectively understood as theory, history or reality, tapping into an inexpressible real.

In many ways, a delusion, a fictive vector, an unexplained hum, a failure, a mishearing, a false sound, what, for example, Eldritch Priest calls 'sorcery', is not the opposite of a fact but rather the idea that the designation of something as fact is a folly in itself. ${ }^{32}$ As Nietzsche tells us of historical facts,

'Facta! Yes, Facta ficta! - A historian has to do, not with what actually happened, but only with events supposed to have happened: for only the latter have produced an effect. Likewise only with supposed heroes. His theme, so-called world history, is opinions about supposed actions and their supposed motives, which in turn give rise to further opinions and actions, the reality of which is however at once vaporised again and produces an effect only as vapour - a continual generation and pregnancy of phantoms over the impentetrable mist of unfathomable reality. All historians speak of things which have never existed except in imagination.' 33 
Fact-fiction, as phono-fiction seems acutely aware of and intent in exposing, are not binary opposites. If even historical facts are rooted in imagination, if the assumption that knowledge alone gives access to truth is nothing but a folly, and if both philosophers and scientists are guilty of routinely promoting this reductionism that, more often than not, sets the human as the end goal whilst presenting certain viewpoints, tastes, and feelings as neutral histories (of science and philosophy) routed in reason, then the proposition holds that fiction too 'might serve the discovery of modal truth' ${ }^{34}$ Or, as Nadine de Courtenay puts it, 'deliberately taking the path of fiction does not entail giving way to illusion. On the contrary, it enables a break with cognitive illusions, with beliefs driven by habit (generated by concealed and still unexplored causal processes pertaining to the context of experience) which operate as dispositions to think and act in an unconsidered manner. Fiction, therefore, appears paradoxically as an essential stage in the conquest of objectivity.' 35

\section{Conclusion}

The value of recognising the entanglements of sound with fiction in order to summon a point of mutation, even derailing, in the sounds studies evolutionary schema, has hopefully started to emerge by now. Taking seriously the proposition that every theory, hypothesis, ontology and discourse is underlined by fabulation, or, in any case, is not the opposite of it, leads to certain useful assumptions; such as, that the theoryfiction wave of thought should not be too readily dismissed as a recent trend, since it is neither recent nor limited to the various new ontologies that have claimed speculation as their own invention. ${ }^{36}$ Moreover, we may conclude that reason always and already includes the irrational and matters of fact are, at the very least, a delirious by-product of the constant creation and vaporisation of a reality that is ultimately unfathomable and impossible. Taking fictional tactics seriously shows, following Meinong and Boltzmann, 'how refusing to comply with the prejudice in favour of the actual can operate as a research strategy conducive to objectivity.' 37

What is potentially interesting, different and subversive about thinking, writing, and making sonically, is the disruption it may conduct to the business as usual of academically producing knowledge, progressing the field and building a cosy network. Alternative methods, such as that of sonic fiction, are useful for shaking up the field of sound studies and its manic preoccupation with the beehive building of databases that mainly transcribe how technologies work and impact on our cultures. The point is that sonic fiction is not interested in participating in the collection and archiving of elements into a field for the purposes of human consumption, but is closer to what Russell Hoban describes writing to be, 'a shamanistic activity taking place in the odd spaces inbetween things...the reality of the flashes and the flickers and the blank spots and the static and the buzzing and the sounds inbetween'. ${ }^{38} \mathrm{As}$ such, it is worth thinking of sound (in all its unsoundness) not merely as a tool of cultural analysis, but rather as this other planet, which, like Solaris, resists scientific inquiry, precise measurement and deviates from our habitual laws. A realm that we can never know and which, far from mirroring our thoughts and practices, mocks the human belief that the world only exists as its mirror. A world without people. One that was always indifferent to us and is, one day, altogether rid of us. Choosing sonic fiction instead of sound studies enables stripping away the anthropomorphism of this planet of sound, but in order to do that, as we learn from planet Solaris itself, we must do away with our all too human selves first: 'Where there are no men there can be no 
motives accessible to men. Before we can proceed with our research either our own thoughts or the materialised forms must be destroyed' 39

Sonic fiction allows us to consider the sonic, the aesthetic, and the fictional, as dimensions of the real on an equal footing with everything else. This is the sonic as productive of reality, activating a continual intersection between creativity and experiment, fiction and fact. Sonic fiction activates a new kind of knowledge, one that demands dismantling and unknowing, what Haraway calls, 'those old saws of Western philosophy and political economics': 'human exceptionalism and bounded individualism'. ${ }^{40}$ As these become, according to her, 'seriously unthinkable: not available to think with', we must look for other, indirect methods, suitable for uncovering unidentified regions of reality. If, as I have argued, the sonic realm exhibits a fundamental indifference towards human affairs, it is because it is better suited to chthonic ones; what Haraway calls 'a rich terran muddle for SF, science fact, science fiction, speculative feminism, speculative fabulation', and, I might add here, Sonic Fiction. Fiction and sound writing reality, activating new rationalities, calling for non-standard, alien methods for conducting a study of the unknown, for the purpose of deepening it. ${ }^{41}$

Books

Ccru, Ccru Writings 1997 - 2003, (Time Spiral Press, Kindle, 2015)

Dorothee Birke, Michael Butter, and Tilmann Köppe, eds, Counterfactual Thinking/ Counterfactual Writing (Germany: Walter de Gruyter, 2011), p.6

Michael Bull and Les Back, eds, Auditory Culture Reader 2nd edition (London, NY: Bloomsbury, 2016), p.1

John Cogburn and mark Allan Ohm, 'Actual Qualities of Imaginative Things, Notes towards an Object-Oriented Literary Theory', in Speculations V: Aesthetics in the 21st Century, Ridvan Askin, Paul J. Ennis, Andreas Hagler, Philipp Schweighauser, eds, (NY: Punctum Books, 2014), pp.22-24

Nadine de Courtenay, 'The epistemological virtues of assumptions: towards a coming of age of Boltzmann and Meinong's objections to 'the prejudice in favour of the actual'? Studies in History and Philosophy of Science, 41 (2010) pp.41-57

Gilles Deleuze, Foucault, [1986], trans. Sean Hand, (London, NY: Continuum, 2006), p.12

Jim Drobnick, ed. 'Introduction' in Aural Cultures (Banff: YYZ, 2004), p.10.

Kodwo Eshun, More Brilliant Than The Sun, (Great Britain: Quartet,1998), pp.6, 138, 38, 5, 4 
Veit Erlmann, Reason and Resonance: a History of Modern Orality, (Cambridge MA: The MIT Press, 2014), pp.17-18

Kodwo Eshun 'Drexciya as Spectre' [2008], in Aquatopia: The Imaginary of the Ocean Deep, Martin Clark and Alex Farquarson, eds, (UK: Tate, 2013), p.138

Michel Foucault, Foucault Live: Collected Interviews, 1961--1984, Sylvere Lotringer, ed, (New York: Semiotext(e), 1996)

Michel Foucault, 'The Thought of the Outside', in Aesthetics, Method, and Epistemology: Essential Works of Foucault, 1954-1984; Volume II, James D. Faubion and Paul Rabinow, eds, (New York: The New Press, 1998), p.149

Michel Foucault, The Archaeology of Knowledge, [1969] Trans. By A.M. Sheridan Smith, (London and NY: Routledge, 2002), p.56

Prudence Gibson, 'Art Theory/ Fiction as Hyper Fly', in Baylee Brits, Prudence Gibson, Amy Ireland, eds, Aesthetics After Finitude, (Melbourne: re.press, forthcoming), p.39

Steve Goodman, Sonic Warfare: Sound, Affect, and the Ecology of Fear, (Cambridge MA: The MIT Press, 2009), p.2

Felix Guattari, The Three Ecologies [1989], trans. by Ian Pindar and Paul Sutton, (London \& New Brunswick: Athlone, 2000), p.12

Graham Harman, 'On the Undermining of Objects: Grant, Bruno, and Radical Philosophy',in Levi Bryant, Nick Srnicek, eds, The Speculative Turn: Continental Materialism and Realism, (Melbourne: re.press, 2011)

Haraway, 'Tentacular Thinking: Anthropocene, Capitalocene, Chthulucene', In e-flux, 75, (September 2016), <http://www.e-flux.com/journal/75/67125/tentacularthinking-anthropocene-capitalocene-chthulucene/ $>$ [08/01/2017]

Michele, Hilmes , 'Is There a Field Called Sound Culture Studies? And Does It Matter? (Review), American Quarterly, 57 (2005), Number 1, pp. 249-259

Douglas Kahn, Noise, Water, Meat, A History of Voice, Sound, and Aurality in the Arts (Cambridge MA: The MIT Press, 1999), p.3

John Kieffer, 'Sound Art: Artists of the new wave', The Independent online, Monday

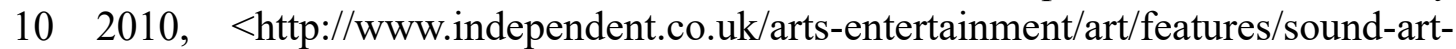
artists-of-the-new-wave-1970453.html $>$ [20/12/2016]

Stanislaw Lem, Solaris, Trans. Joanna Kilmartin and Steve Cox, (New York: Walker, 1970), p.134

David Lewis, 'Postscript to "Truth in Fiction"' in Philosophical Papers I (Oxford: Oxford University Press, 1983), p.278 
Thomas Ligotti, Songs of a Dead Dreamer (Albuquerque, NM: Silver Scarab, 1985), p.142

Marshall McLuhan, in Letters of Marshall McLuhan, Matie Molinaro, Corinne McLuhan, William Toye, eds, (Oxford: Oxford University Press, 1987), p.217

Barrington Nevitt, ABC of Prophecy: Understanding the Environment, (Toronto: Canadian Futures, 1980), pp.82-84.

Friedrich Nietzsche, Daybreak: Thoughts on the Prejudices of Morality, Maudemarie Clark and Brian Leiter, eds, trans. R.J. Hollingdale, (UK: Cambridge University Press, 1997), p.156

Luciana Parisi, Contagious Architecture, (Cambridge MA: THe MIT Press, 2013), ix

Trevor Pinch and Karin Bijsterveld, eds, The Oxford Handbook of Sound Studies (Oxford: Oxford University Press, 2012), p.10

Eldritch Priest, Boring, Formless, Nonsense, (London, NY: Bloomsbury, 2013), p.247

Jacques Rancière, Dissensus: On Politics and Aesthetics, trans. Steven Corcoran, (London, NY: Continuum, 2010), p.149

Alan Sokal and Jean Bricmont, Fashionable Nonsense, Postmodern Intellectual Abuse of Science. (USA: Picador, 1999)

Kathrin Thiele, Thiele, Iris van der Tuin, Cecilia Asberg, 'Speculative Before the Turn', in Cultural Studies Review , 21, (2015), Issue 2, pp.145 - 172

Russell Hoban, in 'Orpheus Underground', Neil Gaiman, BBC Radio 4, $<$ http://www.bbc.co.uk/programmes/b06cw171> [09/01/2017]

Notes

${ }^{1}$ Drobnick, Aural Cultures, 10

'Kieffer, 'Sound art: Artists of the new wave'

${ }^{3}$ Hilmes, 'Is There a Field Called Sound Culture Studies? And Does It Matter?, 249

${ }^{4}$ Eshun, More Brilliant Than the Sun

${ }^{5}$ Kahn, Noise, Water, Meat, 3

${ }^{6}$ Back and Bull, 2016, Auditory Culture Reader $2^{\text {nd }}$ edition, 1

${ }^{7}$ Pinch and Bijsterveld, The Oxford Handbook of Sound Studies, 10

8Erlmann, Reason and Resonance, 17-18

${ }^{9}$ Eshun, More Brilliant, 6.

${ }^{10}$ Eshun, 'Drexciya', 138

${ }^{11}$ Eshun, 138

${ }^{12}$ Goodman, Sonic Warfare, 2

${ }^{13}$ Ccru Writings 1997 - 2003, 9 
${ }^{14}$ Eshun, More Brilliant, 5

${ }^{15}$ Eshun refers to 'MythScience' often in More Brilliant and cites a relevant quote by Virilio 'Science and technology develop the unknown, not knowledge. Science develops what is not rational.' In Eshun, 4

${ }^{16}$ Ligotti, Songs of a Dead Dreamer, 142

${ }^{17}$ AUDINT, Martial Hauntology, vinyl

${ }^{18}$ Guattari, The Three Ecologies, 12

${ }^{19}$ See Parisi 'Preface: Weird Formalism' in Contagious Architecture, ix

${ }^{20}$ In The Ecstasy of Communication, Baudrillard writes, 'The impossibility of reconciling theory with the real is a consequence of the impossibility of reconciling the subject with its own ends. All attempts at reconciliation are illusory and doomed to failure.' See also Nevitt, Abc Of Prophecy, 82-84. Nevitt is one of the main successors to McLuhan's artistic strategy, summed up in a letter to his mother that read, 'The Mechanical Bride is really a new form of science fiction, with ads and comics cast as characters. Since my object is to show the community in action rather than *prove* anything, it can indeed be regarded as a new kind of novel'. McLuhan, Letters, 217

${ }^{21}$ Birke, Butter, and Köppe, Counterfactual Thinking/ Counterfactual Writing, 6

${ }^{22}$ Foucault, Archaeology, 56

${ }^{23}$ Foucault, Foucault Live: Collected Interviews, 24

${ }^{24}$ Deleuze, Foucault, 12

${ }^{25}$ Foucault, Volume 2: Aesthetics, Method, and Epistemology, 149

${ }^{26}$ Eshun, Aquatopia, 138

${ }^{27}$ Rancière, Dissensus: On Politics and Aesthetics, 141

${ }^{28}$ Birke, Butter, and Köppe (eds), Counterfactual Thinking/ Counterfactual Writing, 2

${ }^{29}$ Birke et al, Counterfactual, 6

${ }^{30}$ For an interesting discussion see de Courtenay's article 'The epistemological virtues of assumptions: towards a coming of age of Boltzmann and Meinong's objections to 'the prejudice in favour of the actual'?. Also relevant here are the polemics between sciences and humanities resulting in the 'Science Wars' of the nineties, and the infamous incident of Alan Sokal's journal publishing experiment and attack on the humanities and social sciences, which became his book, with Jean Bricmont, Fashionable Nonsense, Postmodern Intellectual Abuse of Science.

${ }^{31}$ Cogburn and Ohm, Speculations V: Aesthetics in the $21^{\text {st }}$ Century, 224. For a summary of theories of object see Graham Harman, 'On the Undermining of Objects: Grant, Bruno, and Radical Philosophy', 22-24

${ }^{32}$ Eldritch Priest, Boring Formless Nonsense, 247

${ }^{33}$ Nietzsche, Daybreak: Thoughts on the Prejudices of Morality, 156

${ }^{34}$ Lewis, "Postscripts to "Truth in Fiction", 278

${ }^{35}$ de Courtenay, 'The epistemological virtues of assumptions: towards a coming of age of Boltzmann and Meinong's objections to 'the prejudice in favour of the actual?', 56

${ }^{36}$ For a relevant discussion see 'Speculative Before the Turn' by Asberg, Thiele and van Der Tuin.

${ }^{37}$ de Courtenay, 43

${ }^{38}$ Hoban in Gaiman, 'Orpheus Underground', BBC Radio 4

${ }^{39}$ Lem, Solaris, 134

${ }^{40}$ Haraway, 'Tentacular Thinking: Anthropocene, Capitalocene, Chthulucene'

${ }^{41}$ Haraway, 'Tentacular Thinking' 